Mr Milenko Živaljević, pukovnik, dipl. inž.

\section{POUZDANOST BORBENIH AVIONA - SLABO STRUKTURIRANI PROBLEMI I MOGUĆNOSTI ZA NJIHOVO REŠENJE}

Rezime:

$U$ radu su razmatrani slabo strukturirani problemi koji se javljaju u oblasti pouzdanosti sistema borbenih aviona (lovaca bombardera) pri određenoj misiji $i$ predlaže način za njihovo razrešenje. Sa aspekta pouzdanosti avionskih sistema, analizirana su tri karakteristična slučaja: maksimalni dolet, maksimalna pouzdanost izvršenja zadatka, $i$ borbena misija sa upotrebom naoružanja.

Naznačeni su slabo strukturirani problemi $i$ predočeni mogući pravci njihovog razrešenja. U jedno od mogućih rešenja uvrštena je $i$ podela borbenog aviona na sisteme bitne za bezbednost leta $i$ sisteme bitne za izvršenje misije.

Radi određivanja značaja pojedinog sistema za bezbednost leta primenjena je fuzzy logika, uspostavljena su pravila aproksimativnog rezonovanja, izvršena je defazifikacija $i$ predložena promena pouzdanosti.

Ključne reči: borbeni avion, pouzdanost, sistem, fuzzy logika, fuzzy promenljiva.

\title{
RELIABILITY OF COMBAT AIRCRAFT - INCOMPLETELY STRUCTURED PROBLEMS AND POSSIBILITIES FOR THEIR SOLUTION
}

\section{Summary:}

In the article are considered the incompletely structured problems emerging in the field of reliability of combat aircraft (fighter-bombers) in execution of given missions, and a manner of their solution is proposed. With respect to the reliability of the aircraft systems three characteristic cases have been analysed: maximum range, maximum reliability in execution of mission, combat mission with utilization of armament.

Insufficiently structured problems are outlined, and possible courses for their solutions are suggested. One of the possible solutions encomipasses the division of the combat aircraft to systems vital for the flight security and systems vital for execution of mission.

In the definition of significance of individual flight security systems the fuzzy logic is applied, rules of approximate reasoning are established, dephasing is worked out, and change of reliability parameters is suggested.

Key words: combat aircraft, reliability, system, fuzzy logic, fuzzy variable.

\section{Uvod}

Savremeni borbeni avioni (slika 1) predstavljaju veoma složene tehničke sisteme sastavljene od više desetina hi- ljada delova i sklopova. Pratiti njihovu pouzdanost bez uspostavljanja precizne hijerarhije gotovo je nemoguce. Radi određivanja pouzdanosti borbenog aviona i njegovih sistema i kom- 
ponenata neophodno je izvršiti dekompoziciju na sisteme i komponente, odrediti njihovu pouzdanost, a nakon toga izvršiti kvalitetnu integraciju dobijenih pouzdanosti, radi određivanja pouzdanosti aviona.

Imajući to $u$ vidu, neophodna je podela borbenog aviona na sisteme u zavisnosti od njihove funkcije, a oni se, gde je to potrebno, dalje rastavljaju na podsisteme, delove i sklopove, do neophodnog nivoa za praćenje pouzdanosti. Pri tome se moraju izvršiti značajne aproksimacije, vodeći računa da se zadrže generalne karakteristike realnog ponašanja sistema. U
- maksimalni dolet,

- maksimalna pouzdanost pri izvršenju zadatka (misije),

- borbena misija sa korišćenjem vatrenog, bombarderskog ili raketnog naoružanja.

\section{Maksimalni dolet sa stanovišta mehanike leta $i$ sa stanovišta pouzdanosti}

Pod doletom se podrazumeva horizontalna udaljenost koju avion pređe sa određenom količinom goriva [12].

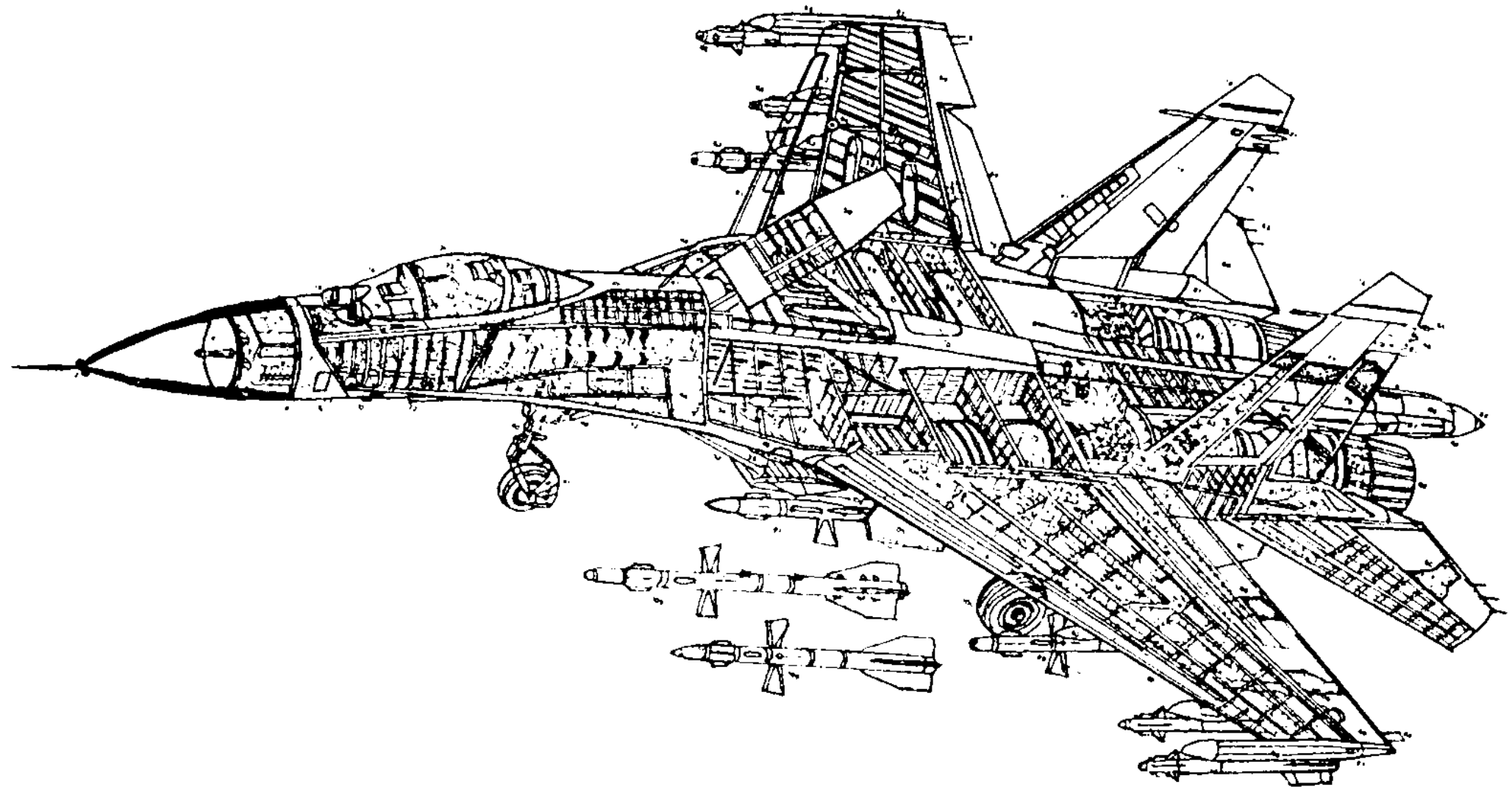

Sl. 1 - Savremeni iovac-bombarder sa velikom autonomijom doleta SU-27

protivnom, nemoguće je stvarati matematičke modele koji bi opisivali sve moguće oblike ponašanja aviona.

\section{Razmatranje promena parametara pouzdanosti avionskih sistema}

Respektujući funkciju cilja borbenog aviona (na primer, lovca-bombardera), moguće je razmatranje promene parametara pouzdanosti avionskih sistema za razne slučajeve leta, od kojih su karakteristični:
$\mathrm{U}$ dolet se uračunava pređeni put $\mathrm{u}$ penjanju i horizontalni let, ali se ne uzima $u$ obzir pređeni put $u$ spuštanju (slika 2).

Dolet koji ostvaruju lovci-bombarderi ima određenih specifičnosti u odnosu na optimalan dolet koji bi se mogao ostvariti ako bi se zanemarila njihova upotreba. Naime, $u$ retkim slučajevima ili skoro nikada se ne ostvaruje let na optimalnoj visini radi povećanja doleta. Obično se borbeni letovi kod ovih aviona, zbog izbegavanja ranog radarskog otkrivanja, izvode po 
principu nisko - nisko - nisko ili nisko - nisko - visoko. U jednom delu leta dolazi i do znatne promene koefici-

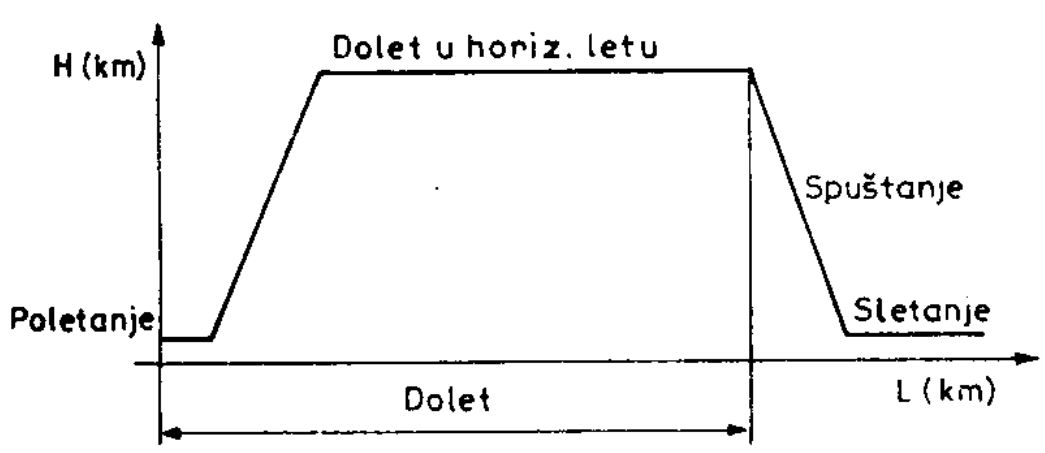

Sl. 2 - Dolet borbenog aviona

jenta otpora, nakon odbacivanja podvešenih ubojnih sredstava, što nije bez uticaja na dolet.

Sa stanovišta pouzdanosti, za ostvarenje maksimalnog doleta, neophodno je da svi sistemi funkcionišu ispravno tokom čitavog leta. Pri tome se podrazumeva potpuno izvršenje zadatka i vraćanje na matični ili drugi aerodrom, bez otkaza.

\section{Maksimalna pouzdanost pri izvršenju zadatka (misije)}

Slučaj leta sa tzv. maksimalnom pouzdanošću ostvaruje se $\mathrm{u}$ figurativnom značenju i ima smisla samo sa stanovišta pouzdanosti. To je slučaj gde se let obavlja sa otkazom nekih (ne bilo kojih) elemenata određenih sistema, kada se uključuju u rad tzv. kvaziredni i kvaziparalelni elementi sistema koji omogućavaju nastavak leta sa pogoršanim performansama do najbližeg aerodroma. U suštini, ovi letovi predstavljaju letenje sa pogoršanim performansama $i$ u nuždi. Kao primeri takvog leta mogu poslužiti otkazi jednog turbomlaznog propulzora (TMP) na avionu sa dva i više TMP, otkazi pojedinih delova sistema (avionskog uređaja za gorivo, uređaja za automatsko kočenje i zaustavljanje aviona, uređaja za kiseonik i drugih), pri čemu se prekida zadatak, ali se zbog korišćenja rezervnih sistema ne dovodi u pitanje opstanak posade $i$ aviona.

\section{Pouzdanost leta sa upotrebom naoružanja}

Većina borbenih letova odvija se uz upotrebu avionskog naoružanja, bilo vatrenog, bombarderskog ili raketnog. Sa stanovišta pouzdanosti, borbeni letovi mogu biti interesantni radi posmatranja pouzdanosti avionskih instalacija naoružanja i pouzdanosti ubojnih sredstava. Avionsko naoružanje može se koristiti posebno (vatreno, bombardersko ili raketno) ili kombinovano (bombardersko - vatreno, odnosno raketno - vatreno).

\section{Dekompozicija borbenog aviona na celine - sisteme radi određivanja njihove pouzdanosti}

Pri izradi matematičkih modela za praćenje pouzdanosti sistema borbenog aviona, neophodno je uočiti da je avion borbeni sistem sastavljen od više složenih strukturalnih celina i da se svaka strukturalna celina može razložiti na više međusobno integrisanih sistema sa određenom interakcijom. Radi stvaranja realnog modela, neophodno je analizirati i obraditi ove zavisnosti, pa je potrebno izvršiti podelu aviona na sledeće celine:

1. zmaj i struktura,

2. hidraulički sistem,

3. avionski uređaj za gorivo,

4. sistem komandi leta,

5. sistem pogonske grupe,

6. sistem elektroopreme,

7. sistem elektronske i merne opreme, zacije,

8. sistem klimatizacije i presuri- 
9. sistem naoružanja (vatreno, raketno i bombardersko),

10. uređaj za kiseonik.

$\mathrm{Na}$ pouzdan rad aviona i izvršenje funkcije cilja presudan uticaj imaju tzv. osnovni energetski sistemi, gde spadaju gorivni sistemi (aviona i TMP), hidraulički sistem i sistem elektroopreme koji služi za napajanje aviona električnom energijom. Oni energijom napajaju većinu sistema na avionu, tako da se bez njihovog pouzdanog funkcionisanja ne može zamisliti ostvarenje nijedne uspešne misije aviona. Više autonomnosti od ovih sistema ima. ju podsistem za ulje i uređaj za kiseonik koji takođe spadaju u energetske sisteme, ali pošto opslužuju sami sebe pridaje im se manji značaj.

\section{Pouzdanost borbenog aviona dobijena integracijom pouzdanosti sistema i komponenata}

Za ocenu pouzdanosti borbenog aviona kao jedinstvenog sistema, neophodno je izvršiti integraciju pouzdanosti njegovih sistema u okviru pomenutih zadataka:

- maksimalnog doleta,

- maksimalne pouzdanosti pri izvršenju zadatka,

- borbene misije sa korišćenjem vatrenog, bombarderskog ili raketnog naoružanja.

Rešenje ovog zadatka, za sada, pripada klasi takozvanih slabo strukturiranih problema. Ne postoje precizno definisana pravila kako izvršiti integraciju pouzdanosti sistema $u$ avion kao celinu. Prema postojećim saznanjima, rešenje ovog problema može se tražiti na dva načina:

- podelom borbenog aviona na sisteme bitne za bezbednost leta i sisteme bitne za uspešno izvršenje misije,
- integracijom pouzdanosti svih sistema borbenog aviona njihovim serijskim povezivanjem i određivanje pouzdanosti aviona samo za vreme trajanja jednog leta, kao što je u literaturi [7] dato za transportne avione.

Prvi predlog u ovom trenutku ima više argumenata za usvajanje. Podelom aviona na sisteme bitne za bezbednost leta i misiju aviona, pouzdanost se računa udruživanjem u serijske veze, ali samo sistema bitnih za bezbednost letenja, dok pouzdanost sistema bitnih za misiju služi za potrebe održavanja po sistemu POPS - sa kontrolom nivoa pouzdanosti. To znači da se problemu praćenja pouzdanosti prilazi selektivno, tj. da pouzdanost aviona istovremeno označava i dostignuti nivo bezbednosti letenja, jer $u$ njoj ne figurišu komponente čiji su otkazi minorni za bezbednost leta, ali se i one drže pod kontrolom i održavaju na optimalan način.

U sisteme bitne za bezbednost leta aviona lovca-bombardera spadaju:

1. zmaj i struktura,

2. hidraulički sistem,

3. avionski uređaj za gorivo,

4. pogonska grupa,

5. elektro-oprema,

6. pojedini podsistemi i komponente elektronske opreme (visinomer, brzinomer i pokazivač položaja aviona).

Sistemi bitni za misiju leta su:

1. svi preostali podsistemi elektronske i merne opreme,

2. klimatizacija i presurizacija,

3. naoružanje (vatreno, bombardersko i raketno),

4. uređaj za kiseonik.

Druga varijanta određivanja pouzdanosti, u koju ulaze svi sistemi i podsistemi, manje je savremena i prihvatljiva, pošto bi u tom slučaju figurisala pouzdanost data za kratak vremenski period, recimo za vreme traja- 
nja jednog leta koji kod lovačko-bombarderske avijacije iznosi i 1 do 1,5 čas. Pouzdanost dobijena na ovaj način bila bi neselektivna i otupljivala bi oštricu zahteva za visokom pouzdanošću najznačajnijih sistema bitnih za bezbednost leta. Inače, podela avionskih sistema i podsistema po prvom principu skoro je neminovna, pošto je neophodno definisati sisteme koji su bitni za uspešno izvršenje misije, a ne utiču značajno na bezbednost leta, zbog održavanja po sistemu POPS - sa kontrolom nivoa pouzdanosti koji je jeftiniji od sistema održavanja po fiksnom resursu ili vremenu.

\section{Određivanje značajnosti sistema za bezbednost leta}

Klasičnom metodom vezivanja sistema $i$ podsistema $u$ serijske veze na avionu, dobijen je neizdiferencirani uticaj sistema na pouzdanost aviona. Naime, dobijena je tehnološka pouzdanost koja je linearna i zavisi isključivo od pouzdanosti elemenata. Odatle i velika opasnost da se pouzdanost borbenog aviona ocenjuje na klasičan način, što bi moglo da unese zabunu $u$ procenjivanju njenog uticaja na bezbednost leta. Sigurno da pouzdanost komandi leta od 0,9 nema isto značenje za preživljavanje aviona kao i pouzdanost kočionog sistema od 0,9 ili ista pouzdanost elektroopreme. Navedene pouzdanosti imaju različite uticaje na preživljavanje aviona na zadatku. Ukoliko se to ne bi shvatilo, avion bi klasičnom teorijom pouzdanosti, kao borbeno sredstvo, bio realno grubo aproksimiran.

Kao što se vidi, navedeni problem samo potencira traženje rešenja u domenu odvajanja pouzdanosti sistema bitnih za bezbednost leta od sistema bitnih za misiju aviona.
Rešenje pouzdanosti komponenata, čija se značajnost za bezbednost leta menja tokom samog leta, primenom fuzzy logike

$\mathrm{Na}$ borbenom avionu postoje uređaji čija se značajnost za bezbednost leta može menjati i u toku samog leta. Očigledan primer za to je pokazivač položaja aviona čiji otkaz u nepovoljnim meteorološkim uslovima znatno smanjuje mogućnost izvršenja borbenog leta. U uslovima dobre vidljivosti, značaj ovog elementa za bezbednost leta je manji. Postavlja se pitanje - kako u ovom slučaju definisati pouzdanost izvršenja zadatka? Klasična teorija pouzdanosti nema rešenja za probleme ove vrste. Ona, za sada, ne razmatra izvore $i$ tipove neizvesnosti koji su posledica nekompletnih informacija, nedovoljno strukturiranih i nejasno definisanih koncepata, konfliktnih izvora podataka i slično.

Kao dopuna klasičnim metodama, često se moraju koristiti metode veštačke inteligencije i ekspertske metode. One se uvode kao alternativa strogim algoritmima u rešavanju realnih, slabo strukturiranih problema. $\mathrm{Za}$ te potrebe koriste se koncepti i ideje veštačke inteligencije, tehnike ekspertskih sistema i metode aproksimativnog rezonovanja koje se zasnivaju na teoriji fuzzy skupova.

Najvažnija osobina metoda veštačke inteligencije i ekspertskih sistema jeste da one uključuju procesiranje znanja kombinovano sa klasičnim procesiranjem podataka, tj. kombinuje se numeričko procesiranje sa simboličkim rezonovanjem nad podacima [9].

$\mathrm{Za}$ opisivanje sistema koriste se lingvističke promenljive (statusne i upravljačke), često nazvane ulazne i izlazne, kojima se, umesto numeričkih, pridružuju lingvističke vrednosti. Relacije između upravljačkih promenljivih $i$ statusnih promenljivih su fuzzy po prirodi, a opisuju se heurističkim pravilima. 
Moguće je generisati pravila koja će modifikovati pouzdanost određenog sistema za svaku kombinaciju deskriptora iz definisanih skupova statusnih promenljivih. U konkretnom slučaju za statusne promenljive, koje su u stanju da ispolje uticaj na pouzdanost sistema aviona, mogu se proglasiti meteorološki uslovi i značajnost sistema za bezbednost leta. $\mathrm{Za}$ upravljačku promenljivu može se proglasiti promena pouzdanosti sa deskriptorima: smanjiti pouzdanost, ne menjati pouzdanost i povećati pouzdanost.

Uvode se sledeće statusne i upravljačke promenljive:

M - fuzzy promenljiva koja označava meteorološke uslove,

Z - fuzzy promenljiva koja označava značajnost sistema za bezbednost leta,

P - fuzzy promenljiva koja definiše promenu pouzdanosti.

Statusna promenljiva značajnost sistema za bezbednost leta zavisi, $\mathbf{u}$ određenim slučajevima, od statusne promenljive meteorološki uslovi, pošto se za određene sisteme značajnost za bezbednost leta menja sa promenom tih uslova. Očigledan primer za to je već pomenuti pokazivač položaja aviona čiji otkaz u nepovoljnim meteorološkim uslovima znatno smanjuje mogućnost izvršenja borbenog leta.

$\mathrm{Za}$ ovaj primer usvojiće se do tri deskriptora, mada ih može biti i više za svaku statusnu promenljivu. Isto će se učiniti i za upravljačku promenljivu:

1. meteorološki uslovi: "nepovoljni«, "povoljni«;

2. značajnost sistema za bezbednost leta: "mala«, "srednja«, "visoka«;

3. promena pouzdanosti sistema: "smanjiti pouzdanost ", "ne menjati pouzdanost", "povećati pouzdanost «.

Subjektivno se procenjuju vrednosti statusnih promenljivih na skali od 0 do 100 , pri čemu važi:
- nula na skali za procenu meteoroloških uslova označava nepovoljne uslove (oblačnost 8/8), a 100 označava povoljne uslove (potpuno vedro). Fuzzy skupovi koji opisuju meteorološke uslove prikazani su na slici 3;

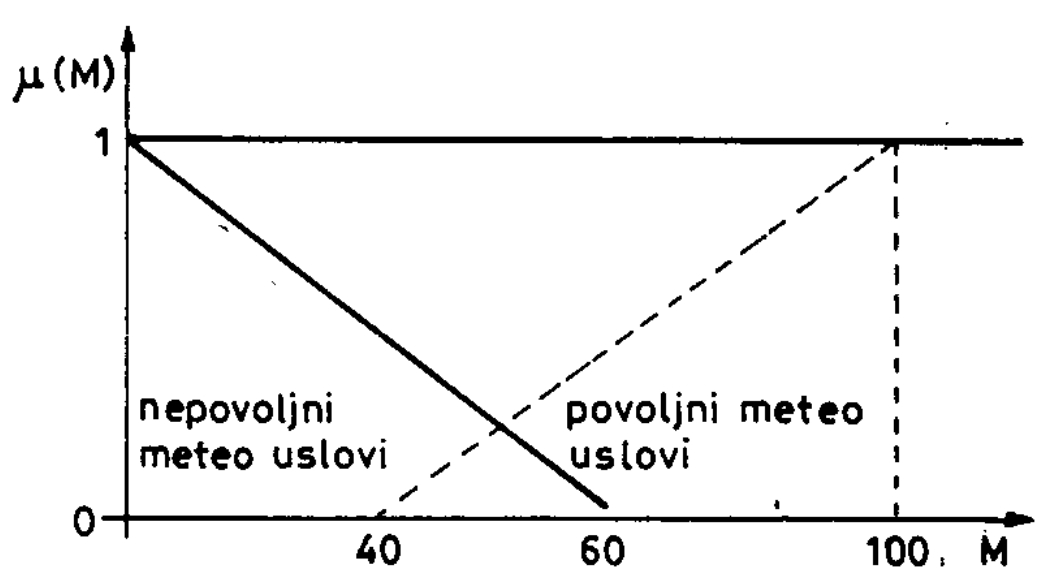

Sl. 3 - Funkcije pripadnosti fuzzy skupova "nepovoljni meteorološki uslovi" $i$ "povoljni meteorološkı uslovi«

- nula na skali za značajnost sistema za bezbednost leta označava da avion može bezbedno da izvrši let i sa otkazom posmatranog sistema, dok 100 na skali označava maksimalnu važnost sistema za bezbednost leta. Fuzzy skupovi koji opisuju značajnost sistema za bezbednost leta prikazani su na slici 4 .

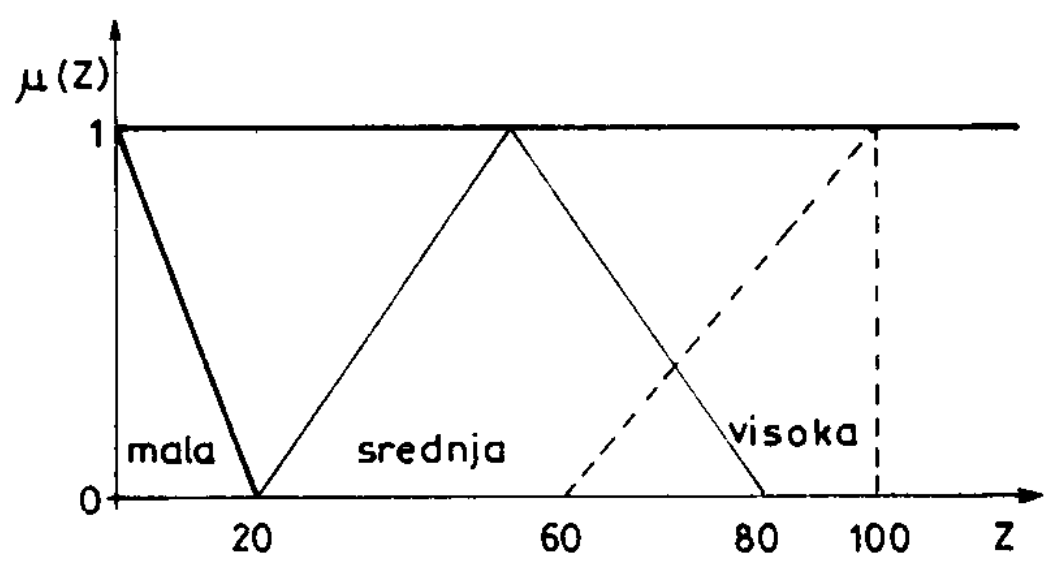

Sl. 4 - Funkcije pripadnosti fuzzy skupova "mala", "srednja" $i$ "velika" znacajnost $z a$ bezbednost leta

Sto se tiče vrednosti za upravljačku promenljivu, kod nje vrednost nula treba da bude predstavljena stepenom pripadnosti 1 fuzzy skupa ne menjati pouzdanost. Granice fuzzy skupova smanjiti pouzdanost i povećati pouzdanost treba da odrede eksperti ko- 
ii dobro poznaju avion i njegovo ponašanje pri otkazu pojedinih sistema. Granice bi trebalo određivati za svaki sistem pojedinačno, u zavisnosti od procene njegovog doprinosa za bozbednost leta. Za navedeni slučaj će se uzeti da se radi o neznatnim korekcijama (povećanje i smanjenje pouzdanosti) za 0,05 , odnosno granice $(0,05 \mathrm{i}-0,05)$, respektivno. Funkcije pripadnosti fuzzy skupova upravljačke promenljive prikazane su na slici 5 .

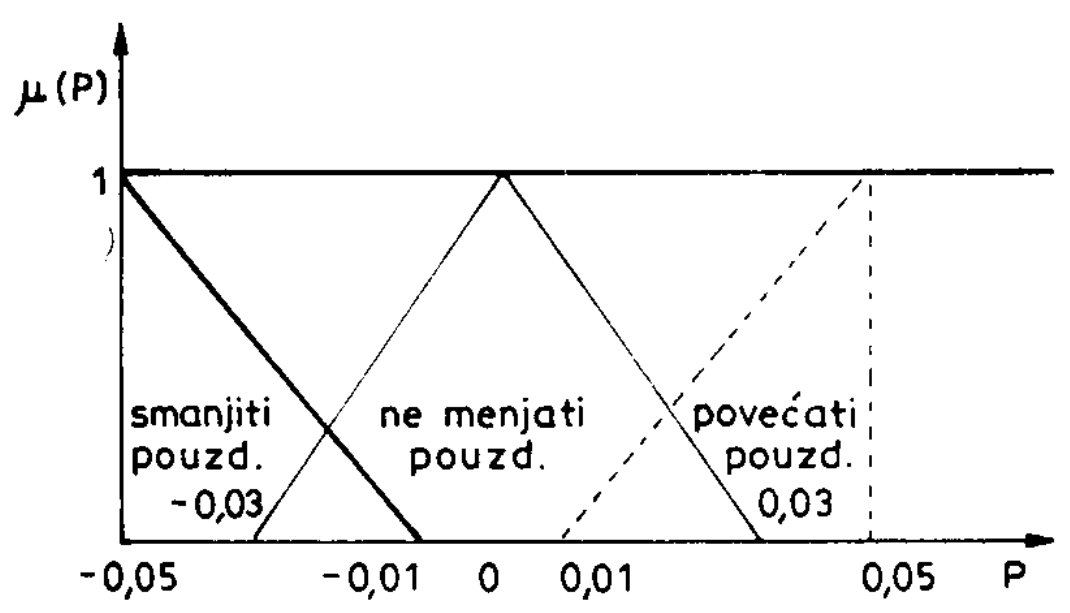

Sl. 5 - Funkcije pripadnosti fuzzy skupova koji opisuju promenu pouzdanosti sistema

Definisanjem broja statusnih promenljivih i njihovih deskriptora definisan je i skup heurističkih pravila, $t j$. njihov broj.

Predlažu se sledeća pravila aproksimativnog rezonovanja, za određivanje upravljačke akcije, po pitanju promene pouzdanosti:

\section{Pravilo 1:}

Ako su $\mathrm{M}$ nepovoljni i $\mathrm{Z}$ mala tada ne menjati pouzdanost, ili

\section{Pravilo 2:}

Ako su $M$ nepovoljni i Z srednja tada ne menjati pouzdanost, ili

\section{Pravilo 3:}

Ako su $\mathrm{M}$ nepovoljni i $\mathrm{Z}$ visoka tada smanjiti pouzdanost, ili

\section{Pravilo 4:}

Ako su M povoljni i $\mathrm{Z}$ mala tada povećati pouzdanost, ili

\section{Pravilo 5:}

Ako su $M$ povoljni i $Z$ srednja tada ne menjati pouzdanost, ili

\section{Pravilo 6:}

Ako su $M$ povoljni i $Z$ visoka tada smanjiti pouzdanost.

Za unapred zadate vrednosti za meteorološke uslove (M) i značajnost sistema za bezbednost leta $(\mathrm{Z})$, primenom izloženog algoritma aproksimativnog rezonovanja svakoj od mogućih vrednosti upravljačke promenljive (P) pridružen je odgovarajući stepen pripadnosti. Primenom metoda centra gravitacije izvršena je defazifikacija, odnosno izbor jedne vrednosti upravljačke promenljive [14].

$\mathrm{Za}$ zadate vrednosti promene meteoroloških uslova i značajnosti sistema za bezbednost leta dobijeni rezultati su prikazani u tabeli 1 .

Praktična vrednost ove tabele, dobijene metodom aproksimativnog rezonovanja, sastoji se u tome što su defazifikacijom određene vrednosti korekcije pouzdanosti u zavisnosti od promene meteoroloških uslova i značajnosti konkretnog sistema za bezbednost leta.

$\mathrm{Na}$ primeru pokazivača položaja može se nedvosmisleno pokazati vrednost metode aproksimativnog rezonovanja. U povoljnim meteorološkim uslovima, ocenjenim na skali sa 95 (skoro $100 \%$ vedro), njegova značajnost za bezbednost leta nije velika, pošto postoji mogućnost vizuelnog određivanja položaja aviona $u$ prostoru i recimo da je ocenjena sa 50 na skali značajnosti za bezbednost leta. Ove dve vrednosti nalaze se $u$ tabeli 1 pod rednim brojem 20. Vidi se da za ovaj 
Korekcija pouzdanosti za promenu meteoroloških uslova i značajnosti sistema za bezbednost leta

\begin{tabular}{|c|c|c|c|}
\hline $\begin{array}{c}\text { Red- } \\
\text { ni } \\
\text { broj }\end{array}$ & $\begin{array}{l}\text { Meteo. } \\
\text { uslovi }\end{array}$ & $\begin{array}{l}\text { Značajnost } \\
\text { za bezbed. } \\
\text { leta }\end{array}$ & $\begin{array}{c}\text { Korekcija } \\
\text { pouzda- } \\
\text { nosti }\end{array}$ \\
\hline 1. & 10 & 95 & $-0,04$ \\
\hline 2. & 30 & 10 & 0,00 \\
\hline 3. & 30 & 40 & 0,00 \\
\hline 4. & 30 & 50 & 0,00 \\
\hline 5. & 30 & 70 & $-0,01$ \\
\hline 6. & 30 & 90 & $-0,03$ \\
\hline 7. & 50 & 10 & 0,01 \\
\hline 8. & 50 & 40 & 0,00 \\
\hline 9. & 50 & 50 & 0,00 \\
\hline 10. & 50 & 70 & $-0,01$ \\
\hline 11. & 50 & 90 & $-0,03$ \\
\hline 12. & 80 & 10 & 0,03 \\
\hline 13. & 80 & 40 & 0,00 \\
\hline 14. & 80 & 50 & 0,00 \\
\hline 15. & 80 & 70 & $-0,01$ \\
\hline 16. & 80 & 90 & $-0,04$ \\
\hline 17. & 95 & 5 & 0,04 \\
\hline 18. & 95 & 10 & 0,03 \\
\hline 19. & 95 & 40 & 0,00 \\
\hline 20. & 95 & 50 & 0,00 \\
\hline 21. & 95 & 70 & $-0,01$ \\
\hline 22. & 95 & 90 & $-0,04$ \\
\hline
\end{tabular}

slučaj leta ne bi trebalo vršiti nikakve korekcije pouzdanosti sa aspekta bezbednosti leta.
U nepovoljnijim meteorološkim uslovima dolazi i do promene značajnosti pokazivača za bezbednost letenja, pošto je on jedini merodavni uređaj za definisanje položaja aviona $u$ prostoru. Ako se pretpostavi da je meteorološka situacija ocenjena sa 30 i značajnost za bezbednost leta je porasla i ocenjena sa 90 . Iz tabele 1 za naznačene vrednosti (red. br. 6), uočava se neophodnost korekcije pouzdanosti za ovaj slučaj leta i to za $-0,03$. Primer je više kolokvijalan nego što na određeni način uspostavlja prave vrednosti upravljačke promenljive (korekciju pouzdanosti) za navedeni slučaj. Za definisanje pravih vrednosti korekcije pouzdanosti za svaki uređaj ili sistem trebalo bi koristiti znanja eksperata (pilota VOC-a), uz čiju bi se pomoć definisale funkcije pripadnosti fuzzy skupova za upravljačke promenljive.

\section{Zaključak}

Zbog specifičnosti i složenosti prostora $\mathrm{i}$ uslova $\mathrm{u}$ kojima borbeni avioni izvršavaju zadatke, postoji niz slabo strukturiranih problema u njihovoj pouzdanosti na koje klasična teorija ne daje rešenja koja zadovoljavaju zahteve prakse. Ilustrovani primer sa pokazivačem položaja samo potvrđuje konstataciju da klasičnim pristupom nisu obuhvaćeni svi relevantni faktori objektivnog karaktera, od kojih zavisi pouzdanost izvršenja zadatka. Integrisanje pouzdanosti sistema radi dobijanja pouzdanosti aviona, kao i određivanje koeficijenata pogoršanja performansi kod kvazirednih i kvaziparalelnih veza, takođe, spadaju $u$ domen slabo strukturiranih problema.

Vrednost dobijenih rezultata se ne minimizira primenjenom metodom aproksimativnog rezonovanja već naprotiv, ovaj način se za sada ukazuje kao jedina alternativa za rešenje navedenih problema. 
Ovakva rešenja, svojom elastičnošću, doprinose da se pouzdanost iz svog isključivo tehnološkog i kvantitativnog prostora premešta $\mathrm{u}$ sferu kvalitativnog, stvarajući tako korelaciju između tehnološke pouzdanosti i bezbednosti leta.

Rešenjem slabo strukturiranih problema iz oblasti pouzdanosti borbenih aviona, na ovaj način, stvoren je ekspertski sistem koji se dalje može koristiti po potrebi.

Dalji prodor u razrešenju navedenih problema moguć je uz aktivno učešće eksperata, što je i jedna od mana navedene metode.

\section{Literatura:}

[1] Adamović, ž. Logistički sistem ođržavanja, Privredni pregled, Beograd, 1989.

[2] Barzilovič, E. J. i grupa autora: Nadežnost aviacionih sistem, Visšaja škola, Moskva, 1982.

[3] Dragović, T., Rašuo B.: Savremeni koncept vazduhoplovnotehničkog obezbeđenja, Mašinski fakultet, Beograd, 1994.

[4] Ivanović, G., Stanivuković, D.: Pouzdanost, Tehnička uprava SSNO, 1988.

[5] Kaufmann, A, Gupta, M.: Introduction to fuzzy arithmetic, Van Nostrand Reinhold Company, New York, 1985.

[6] Kokanović, M., Cirović, M., Modrić, Z.: Logističko inženjerstvo, CVT's KoV, Zagreb, 1985.

[7] Kostočkin V. V.: Nadežnost aviacionih dvigatelej i silovih ustanovok, Mašinostroenie, Moskva, 1976.

[8] Minić, S.: Dinamički model preventivnog održavanja prema stanju motornih vozila, Doktorska disertacija, Mašinski fakultet, Beograd, 1993.

[9] Petrović, R., Vujošević, Petrović, D.: Optlmizacija redudantnih sistema, Saobraćajni fakultet Univerziteta u Beogradu, 1993.

[10] Petrović, R.: Fuzzy skupovi i fuzzy logika u analizi pouzdanosti, Naučni skup Efektivnost sistema i logistika, Mašinski fakultet, Beograd, 1993.

[11] Radojević, D.: Soft computing, SYM-OP-IS 94, Kotor, 1994.
[12] Rendulić, Z.: Mehanika leta, Biblioteka Pravila i udžbenici, 1987.

[13] Rosenhead, J.: Problem structuring methods, EURO XIII/OR 36, University strathclyde, Glasgow, 1994.

[14] Teodorović, D., Kikuchi, S.: Fuzzy skupovi i primene u saobraćaju, Saobraćajni fakultet Univerziteta u Beogradu, 1991.

[15] Teodorović, D., Kalić, M., Pavković, G.: The potential for using set theory in airline network design, Transpn. Res.-B. Vol. 28B, No 2, 1994 EIsevier Science Ltd Printed in Great Britain.

[16] Todorović, J.: Održavanje tehničkih sredstava u RV i PVO, Informativno predavanje za komandni sastav, Beograd, 13. april 1995. godine.

[17] Tođorović, J.: Inženjerstvo održavanja tehničkih sistema, Jugoslovensko društvo za motore i vozila, Novi Beograd, 1993.

[18] Vujanović, N.: Istraživanje metoda ocene i alokacije pouzdanosti i pogodnosti održavanja na primeru jednog sistema naoružanja, Doktorska disertacija, Mašinski fakultet, Beograd, 1983.

[19] Vujanovć, N.: Teorija pouzdanosti tehničkih sistema, Vojnoizdavački i novinski centar, Beograd, 1990.

[20] Živaljević, M., Kalić, M., Pavković, G.: Pouzdanost sistema za zaustavljanje i automatsko kočenje borbenog aviona i mogućnost određivanja koeficijenata pogoršanja performansi primenom fuzzy logike, Vojnotehnicki glasnik br. 6, 1994. 